- him shows how computers can inspire, rather than obviate, human creativity.

In Deep Thinking, Kasparov also delves into the renaissance of machine learning, an AI subdomain focusing on generalpurpose algorithms that learn from data. He highlights the radical differences between Deep Blue and AlphaGo, a learning algorithm created by my company DeepMind to play the massively complex game of Go. Last year, AlphaGo defeated Lee Sedol, widely hailed as the greatest player of the past decade. Whereas Deep Blue followed instructions carefully honed by a crack team of engineers and chess professionals, AlphaGo played against itself repeatedly, learning from its mistakes and developing novel strategies. Several of its moves against Lee had never been seen in human games - most notably move 37 in game 2, which upended centuries of traditional Go wisdom by playing on the fifth line early in the game.

Most excitingly, because its learning algorithms can be generalized, AlphaGo holds promise far beyond the game for which it was created. Kasparov relishes this potential, discussing applications from machine translation to automated medical diagnoses. AI will not replace humans, he argues, but will enlighten and enrich us, much as chess engines did 20 years ago. His position is especially notable coming from someone who would have every reason to be bitter about AI's advances.

His account of the Deep Blue match itself is fascinating. Famously, Kasparov stormed out of one game and gave antagonistic press conferences in which he protested against IBM's secrecy around the Deep Blue team and its methods, and insinuated that the company might have cheated. In Deep Thinking, Kasparov offers an engaging insight into his psychological state during the match. To a degree, he walks back on his earlier claims, concluding that although IBM probably did not cheat, it violated the spirit of fair competition by obscuring useful information. He also provides a detailed commentary on several crucial moments; for instance, he dispels the myth that Deep Blue's bizarre move 44 in the first game of the match left him unrecoverably flummoxed.

Kasparov includes enough detail to satisfy chess enthusiasts, while providing a thrilling narrative for the casual reader. Deep Thinking delivers a rare balance of analysis and narrative, weaving commentary about technological progress with an inside look at one of the most important chess matches ever played.

Demis Hassabis is the founder and chief executive of DeepMind, a neuroscienceinspired AI company based in London.

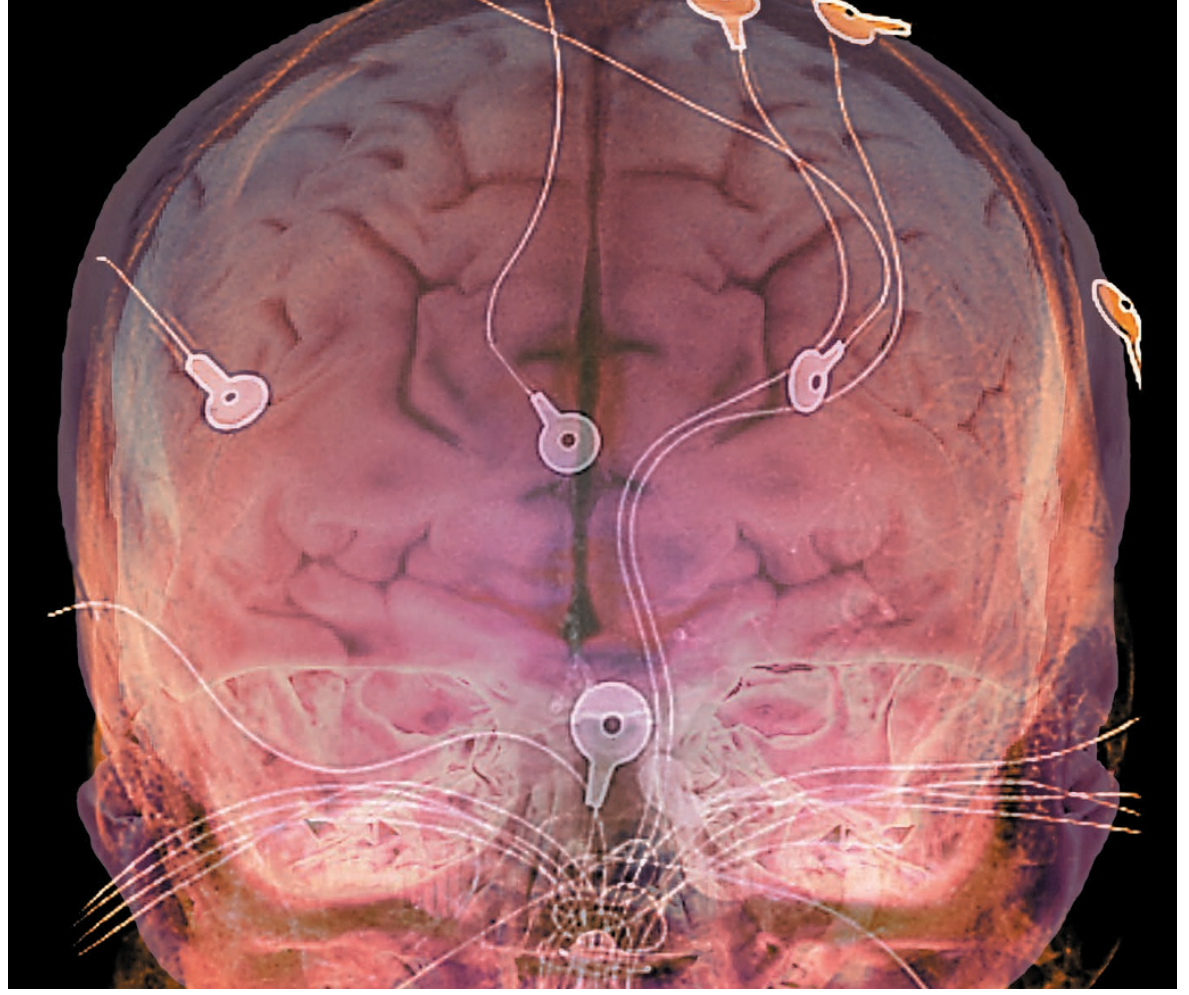

An angiogram and computed-tomography scan of a man's brain, used to locate his language centre.

\title{
PSYCHOLOGY
}

\section{Science in spite of itself}

\section{Barbara A. Spellman hails an analysis of reproducibility in psychology by a champion for change.}

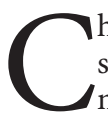
hris Chambers's portrait should sit high on the wall of heroes in the movement to reform science. A cognitive neuroscientist and psychologist, Chambers has had an important role as an editor and advocate in identifying, challenging and changing practices responsible for the reproducibility crisis.

Many fields of science - social, life, physical and medical - have had to acknowledge in recent years that much of their published research is not replicable (see M. Munafò Nature 543, 619-620; 2017). Psychological science was hit hard by that problem early this decade. But it quickly joined the vanguard of reform. In The Seven Deadly Sins of Psychology - part history, part autobiography, largely manifesto - Chambers identifies some "sins", from biased reasoning to outright fraud, that led us to this point. And he describes specific reforms, some already well under way, that will make science more transparent, accessible and reproducible. As he shows, the sins are (mostly) not those of individual scientists, but of the processes and incentive structures under which scientists work.

Chambers ably illustrates these failings with tales from psychological science. The first chapter describes a 2011 paper by social psychologist Daryl Bem that reported nine experiments demonstrating evidence of precognition - the ability to predict the future

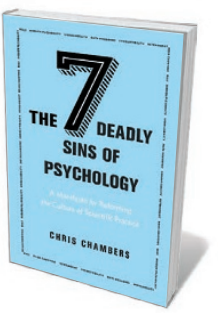

The Seven Deadly Sins of Psychology: A Manifesto for Reforming the Culture of Scientific Practice CHRIS CHAMBERS Princeton University Press: 2017.
(D. J. Bem J. Pers. Soc. Psychol. 100, 407-425; 2011). Published in the American Psychological Association's prestigious Journal of Personality and Social Psychology, it left many psychologists outraged. The article had followed the rules of scientific practice. Its studies all supported the same hypothesis; its methods included randomization and standard-looking data analyses. But close scrutiny of the paper and subsequent failures to replicate the studies (plus the unwillingness of journals to publish those failures) revealed many of the sins.

The sin that makes the biggest news splash is outright fraud - changing or fabricating data, or making up an entire study. It may be the least interesting (and, we hope, the least prevalent) $\sin$, but is illustrated by Chambers's tale of a psychologist who did just that - at least 58 times. If you stop to ask why a scientist would commit fraud, the perverse nature of scientific processes 
and incentives is revealed. To get jobs, promotions, grants or fame, a scientist must publish in high-visibility journals. That is not straightforward. It is not enough to invent an experiment; design, run, and analyse it flawlessly; and write a paper that describes the results clearly. What's also needed are beautiful data that tell an unblemished, consistent story in support of the hypothesis. No amount of care or cleverness can guarantee such results.

Even honest researchers may consciously or unconsciously engage in lesser sins to get better-looking (rather than better) results. They might use biased reasoning and hidden flexibility in deciding how to collect (or not) more data, in reporting (or not) all measures and findings, and in modifying their hypotheses to fit the data. Such decisions might be good for scientists in the short run. They are not good for science.

Chambers is a fan of preregistration as a corrective. With this, scientists describe a proposed study in detail, submit it to a journal for review and potentially get an 'in-principle acceptance'. After running the study and making the data publicly available, a manuscript that fulfils the proposal will be published - regardless of how the data turn out. This could help reduce many of the sins, such as bias, flexibility and some fraud; file drawers filled with studies that 'don't work'; and bean counting, or evaluations concerned with numbers (such as quantity of publications) rather than quality.

Preregistration can't ameliorate all sins, but Chambers provides examples of concrete steps that can be taken by a variety of stakeholders: be more aware of potential biases; share methods and data; push for and reward transparency and openness.

This book is written for anyone curious about how science might repair itself. It should be required reading in university courses on research methods. And it's for publishers, grant funders, journalists and science writers. Enabling, creating and disseminating good science is a vast cooperative endeavour.

Is there still a crisis? Certainly more research will be found to be unreplicable and more theories will unravel. Yet it's key to recall that 'crisis mode' in an epidemic can dissipate as successful treatments evolve, even when new cases arise. As Chambers shows, we think we know the causes and can abate much of the problem. Crisis phase over (in my view). But there is still much work to be done.

Barbara A. Spellman is professor of law and of psychology at the University of Virginia in Charlottesville. From 2011 to 2015, she was editor-in-chief of Perspectives on Psychological Science.

e-mail:bas6g@eservices.virginia.edu

\section{Books in brief}

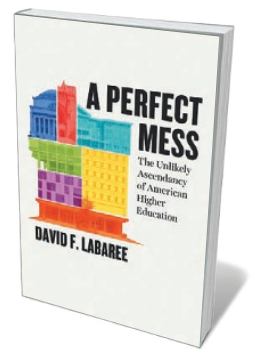

\author{
A Perfect Mess: The Unlikely Ascendancy of American Higher \\ Education \\ David F. Labaree UNIVERSITY OF CHICAGO PRESS (2017)
}

How did a ragbag of colleges become a towering assemblage of world-class universities? In this deft history, David Labaree tracks the evolution of the US higher-education system, an unwieldy array that nevertheless produced $40 \%$ of Nobel laureates between 1901 and 2013. US economic ascendancy, the rise of English as a lingua franca and postwar research funding all played a part; but the fulcrum was the autonomy and strangely effective "anarchic complexity" of the system itself. As Labaree asks, "Why ruin a perfect mess?"

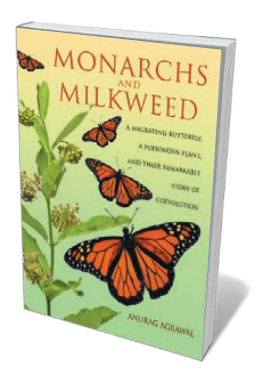

Monarchs and Milkweed

Anurag Agrawal PRINCETON UNIVERSITY PRESS (2017)

From its tigerish beauty and epic 5,000-kilometre migration to its evolutionary arms race with the toxic milkweed plant, North America's monarch butterfly (Danaus plexippus) is a scientific superstar. Ecologist Anurag Agrawal's in-depth study draws on his own research and that of pioneers such as Lincoln Brower to elucidate plant, insect and their evolving defence and counterdefence. His analysis of the monarch's severe decline is nuanced, suggesting that dwindling nectar sources and deforestation in overwintering sites may be culprits, along with milkweed loss.

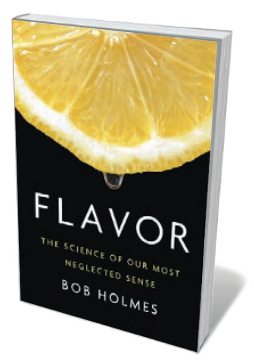

\section{Flavour: The Science of Our Most Neglected Sense}

Bob Holmes W. W. NORTON (2017)

If you can't distinguish a Fuji apple from a Gala on taste alone, join the crowd. As Bob Holmes notes, most of us waft through life barely cognizant of the sensory riches concocted by nose, tongue and mouth. Mining the boom in the science of flavour, Holmes reveals how it takes a "committee" of lingual receptors to taste bitterness; is stumped by a smell halfway between Cheddar cheese and turpentine in an olfaction test; and ponders why chewing a Sichuan peppercorn seems to set off a 50 -hertz vibration in his mouth. $A$ prodigious and delectable feast of accessible science.

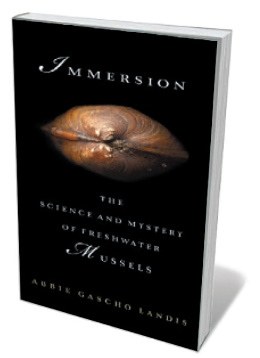

Immersion: The Science and Mystery of Freshwater Mussels Abbie Gascho Landis ISLAND (2017)

Heelsplitter, shineyrayed pocketbook, fatmucket: to inspire such monikers, the freshwater mussels of the US southeast must be charismatic indeed. And so it proves in veterinary surgeon and writer Abbie Gascho Landis's eloquent treatise. She snorkelled through creeks and packed in lab time to study the water-filtering bivalves and their intriguing behaviours - such as bundling their larvae into minnow-shaped lures to hitch rides on hungry fish. Yet with $70 \%$ of 300 species imperilled and US waterways under pressure, Landis's book is as much call to action as paean to mesmerizing molluscs.

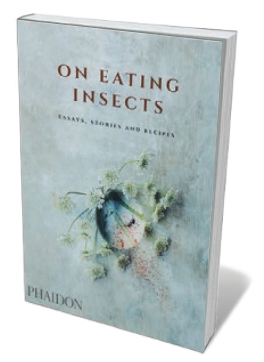

On Eating Insects: Essays, Stories and Recipes

Josh Evans, Roberto Flore, Michael Bom Frøst and Nordic Food Lab PHAIDON (2017)

Sometimes, only spicy cricket and asparagus (with lacto-fermented pea water) will do - if, that is, you snack on the wild side. This big, beautifully illustrated compendium on entomophagy by food researchers Josh Evans, Roberto Flore and Michael Bom Frøst (with the experimental Nordic Food Lab) offers techniques and tasting notes gleaned from global fieldwork, and tongue-boggling recipes. A gem for the curious, or anyone craving an ant-larvae taco. Barbara Kiser 